\title{
A review of controlled trials of acupuncture for women's reproductive health care
}

\author{
A R White, MA, BM BCh, Senior Lecturer, Complementary Medicine, Institute of Health and Social Care Research, Peninsula \\ Medical School, Exeter, UK
}

Correspondence: $\operatorname{Dr}$ A $R$ White, Complementary Medicine, Institute of Health and Social Care Research, Peninsula Medical School, 25 Victoria Park Road, ExeterEX2 4NT, UK.E-mail: Adrian.White@pms.ac.uk

(Accepted 4 June 2003)

Journal of Family Planning and Reproductive Health Care 2003; 29(4): 233-236

\begin{abstract}
Background. Acupuncture as a therapy, and acupressure as self-treatment, are increasingly widely used for gynaecological conditions, and this study aims to review the scientific literature on their effectiveness.

Method. A systematic review of controlled trials of acupuncture or acupressure for gynaecological conditions, published in a European language.

Synthesis. No studies in mastalgia, menorrhagia, pelvic pain, premenstrual syndrome or vulvodynia met the inclusion criteria. Four studies, two of which were patientblinded, of acupuncture or acupressure for dysmenorrhoea suggest that it may have an effect. Three studies of acupuncture given at various stages of infertility treatment are promising, but none was patient-blind. Two studies of acupuncture for menopausal symptoms showed no effect during the treatment period when compared with sham acupuncture, and a third study showed no effect on hypertension in postmenopausal women, though some improvement in symptoms was noted.

Conclusion. In view of the small number of studies and their variable quality, doubt remains about the effectiveness of acupuncture for gynaecological conditions. Acupuncture and acupressure appear promising for dysmenorrhoea, and acupuncture for infertility, and further studies are justified.
\end{abstract}

Key message points

- Acupuncture is increasingly widely used to treat gynaecological conditions.

- Few rigorous studies have been performed in the use of acupuncture in gynaecological conditions and firm conclusions on effectiveness are not possible.

- Evidence suggests that acupuncture for dysmenorrhoea and infertility is promising and further studies are justified.

\section{Introduction}

Acupuncture is widely available in the $\mathrm{UK},{ }^{1}$ both privately and through the National Health Service (NHS). ${ }^{1}$ It is most commonly used to treat chronic pain, although there is still a lack of good evidence of its efficacy for this condition. ${ }^{3}$ The evidence that acupuncture is superior to placebo is strongest in the treatment of postoperative nausea. ${ }^{4}$ One reason why patients and health care staff are attracted to acupuncture is that it has a very low level of serious adverse events when given by qualified practitioners. 5

Many acupuncture practitioners use an approach based on the concepts of traditional Chinese acupuncture, and believe that the needles correct any imbalances in the flow of life force along meridians. In contrast, many medical, nursing and physiotherapy staff use a Western approach, arguing that the effects of acupuncture can be adequately explained by the fact that the needles stimulate the nervous system in a particular way. There is now good evidence that acupuncture may lead to a release of neurotransmitters, especially beta-endorphin and serotonin, ${ }^{6}$ in several parts of the brain. These transmitters are involved in descending inhibitory pain control. Another possible mechanism for pain control, but one that awaits confirmation, ${ }^{7}$ holds that the needles inactivate 'trigger points' in muscles. Trigger points are areas of chronic hyperactivity, initially resulting from physical injury or microtrauma, that may continue to cause pain for many years. Acupuncture may also produce effects through local changes in the tissues, e.g. stimulating blood flow.

There are several techniques allied to acupuncture. These include acupressure (shiatsu) in which appropriate points are massaged by the fingers, thumbs or knuckles. Acupressure may also be self-administered (for example, using the familiar wristbands for nausea). Another technique, namely electroacupuncture, involves stimulating the acupuncture needles by battery-powered pulse generators. This is superficially similar to transcutaneous electrical nerve stimulation (TENS), particularly low-frequency TENS. However, there are considerable differences, such as the effect of TENS being rarely sustained whereas the benefits of a successful course of acupuncture frequently are.

It has to be admitted that acupuncture has the attributes of a good placebo (Oriental mystique, skin penetration, novelty). It is easy to dismiss reports of benefit as purely due to placebo, so convincing evidence for acupuncture only comes from comparing it to a placebo control. The placebo must appear to the patient to be like a needle, in order to have the same psychological impact. Many inventive solutions have been tried,${ }^{8}$ the commonest being insertion of needles superficially and in the wrong location. However, even this might not qualify as a totally inactive placebo. ${ }^{9}$ Recently, a blunt needle that recoils into the handle has been invented. ${ }^{10,11}$ It appears to enter the body but actually only presses on the skin. Its use should lead to more and better evidence.

Gynaecological conditions are among the top six conditions for which acupuncture is used by doctors. ${ }^{12}$ This paper is a review of controlled trials of the effectiveness of acupuncture and acupressure in women's reproductive health excluding pregnancy.

\section{Methods}

MEDLINE and EMBASE databases and the Cochrane Library were searched using the terms acupuncture or acupressure, and dysmenorrhoea, infertility, mastalgia (mastodynia), menopause, menorrhagia, pelvic pain, premenstrual or vulvodynia. In addition, files in the author's office were searched. The search was restricted to 
Table 1 Description of studies included in the review

\begin{tabular}{|c|c|c|c|c|c|c|c|c|c|c|}
\hline Study & Design & Blinding & $\begin{array}{l}\text { Population } \\
\text { group }\end{array}$ & Intervention & $\mathrm{n}$ & $\begin{array}{l}\text { Comparison } \\
\text { group }(\mathrm{s})\end{array}$ & $\mathrm{n}$ & Outcome & $\begin{array}{l}\text { Follow- } \\
\text { up }\end{array}$ & Result \\
\hline $\begin{array}{l}\text { Dysmenorrhoea } \\
\text { Helms }(1987)^{13}\end{array}$ & RCT & Patient (partial) & Gynae clinic & $\begin{array}{l}\text { Traditional } \\
\text { acupuncture }\end{array}$ & 11 & $\begin{array}{l}\text { Non-point } \\
\text { acupuncture; } \\
\text { usual care; } \\
\text { visitation }\end{array}$ & $\begin{array}{l}11 \\
11 \\
10\end{array}$ & $\begin{array}{l}\text { Menstrual } \\
\text { symptom } \\
\text { score (diary) }\end{array}$ & 1 year & $\begin{array}{l}\text { NSD in scores (more } \\
\text { than } 50 \% \text { responders } \\
\text { with acupuncture) }\end{array}$ \\
\hline $\begin{array}{l}\text { Taylor et al. } \\
(2002)^{16}\end{array}$ & $\mathrm{RCT}$ & No & NS & $\begin{array}{l}\text { Acupressure } \\
\text { garment }\end{array}$ & 31 & Usual care & 27 & $\begin{array}{l}\text { Menstrual pain } \\
\text { and medication } \\
\text { diary }\end{array}$ & None & $\begin{array}{l}\text { Acupressure superior } \\
(\mathrm{p}<0.05)\end{array}$ \\
\hline $\begin{array}{l}\text { Pouresmail and } \\
\text { Ibrahimzadeh } \\
(2002)^{17}\end{array}$ & RCT & Patient (partial) & Schoolgirls & Self-acupressure & 72 & $\begin{array}{l}\text { Sham } \\
\text { acupressure; } \\
\text { ibuprofen }\end{array}$ & $\begin{array}{l}72 \\
72\end{array}$ & $\begin{array}{l}\text { Pain VAS; } \\
\text { dysmenorrhoea } \\
\text { grade }\end{array}$ & None & $\begin{array}{l}\text { Acupressure and } \\
\text { ibuprofen significantly } \\
\text { superior to sham } \\
\text { acupressure } \\
(\mathrm{p}<0.0001)\end{array}$ \\
\hline $\begin{array}{l}\text { Infertility } \\
\text { Stener-Victorin } \\
\text { et al. }(1999)^{18}\end{array}$ & RCT & No & IVF centre & $\begin{array}{l}\text { Electro- } \\
\text { acupuncture }\end{array}$ & 75 & $\begin{array}{l}\text { Usual } \\
\text { alfentanil } \\
\text { analgesia }\end{array}$ & 75 & $\begin{array}{l}\text { (Analgesia); } \\
\text { take-home } \\
\text { baby rate }\end{array}$ & None & $\begin{array}{l}\text { Acupuncture } \\
\text { significantly } \\
\text { superior }(\mathrm{p}<0.05)\end{array}$ \\
\hline $\begin{array}{l}\text { Gerhard and } \\
\text { Postneek (1992) }\end{array}$ & $\begin{array}{l}\text { Matched } \\
\text { pairs }\end{array}$ & No & Gynae clinic & $\begin{array}{l}\text { Auriculo- } \\
\text { acupuncture }\end{array}$ & 45 & $\begin{array}{l}\text { Hormone } \\
\text { therapy }\end{array}$ & & Pregnancy rate & 3 months & NSD \\
\hline $\begin{array}{l}\text { Paulus et al. } \\
(2002)^{20}\end{array}$ & $\mathrm{RCT}$ & No & $\begin{array}{l}\text { Assisted } \\
\text { reproduction }\end{array}$ & $\begin{array}{l}\text { Formula } \\
\text { acupuncture }\end{array}$ & 80 & Usual care & 80 & Pregnancy rate & None & $\begin{array}{l}\text { Acupuncture } \\
\text { significantly superior } \\
(\mathrm{p}=0.03)\end{array}$ \\
\hline $\begin{array}{l}\text { Menopausal symp } \\
\text { Wyon et al. } \\
(1995)^{29}\end{array}$ & $\begin{array}{r}\text { toms } \\
\text { RCT }\end{array}$ & Patient & Gynae clinic & $\begin{array}{l}\text { Electro- } \\
\text { acupuncture }\end{array}$ & 11 & $\begin{array}{l}\text { Superficial } \\
\text { acupuncture }\end{array}$ & 10 & $\begin{array}{l}\text { Flush scores, } \\
\text { Kupperman index }\end{array}$ & 3 months & NSD \\
\hline $\begin{array}{l}\text { Sandberg et al. } \\
(2002)^{21}\end{array}$ & RCT & Patient & $\begin{array}{l}\text { Gynae clinic, } \\
\text { media }\end{array}$ & $\begin{array}{l}\text { Electro- } \\
\text { acupuncture }\end{array}$ & 15 & $\begin{array}{l}\text { Superficial } \\
\text { acupuncture }\end{array}$ & 15 & $\begin{array}{l}\text { Flush scores, } \\
\text { well-being }\end{array}$ & 6 months & NSD \\
\hline
\end{tabular}

BP, blood pressure; gynae, gynaecological; IVF, in vitro fertilisation; NA, not applicable; NS, not stated; NSD, no significant difference; RCT, randomised controlled trial; VAS, visual analogue score.

European languages. The full article was retrieved for any reference that appeared from the title or abstract to report a controlled trial. Predetermined trial data were extracted into a table.

\section{Results}

No controlled trials were located for mastalgia, menorrhagia, pelvic pain (as a primary diagnosis), premenstrual or vulvodynia. Results for the remaining three clinical areas are given in Table 1 and are reviewed here.

\section{Dysmenorrhoea}

One small trial of acupuncture for dysmenorrhoea included 48 women with an average age of 28 years. ${ }^{13}$ After referral to an acupuncturist by the Gynaecology Clinic in Oakland, CA, USA, the women were randomised into four groups. The treatment group received real acupuncture using traditional points on the legs and abdomen, and one point on the wrists, to a total of 12 needles. The acupuncture control group were given sham acupuncture with needles placed in non-point, non-meridian sites on the legs and arms. Both these groups received treatment each week (except during menstruation) for 12 weeks. A second control group had no further contact with the physician. A third control group served as 'visitation control', and attended the physician's clinic three times, at monthly intervals, for a review of symptoms and discussion. All patients kept diary records of menstrual symptoms immediately before joining the study and over the course of a year. Patients were classified as 'improved' if their mean pain scores were reduced by at least $50 \%$. A total of 43 patients provided follow-up data. There was a significant fall in reported pain in the real acupuncture group, a smaller fall in the sham acupuncture group, and smaller falls still in the two groups who received no acupuncture (see Table 2). The success rate was significantly higher in the acupuncture group; the difference in mean pain scores was not significant, but that may be because of a type II error.

A second randomised controlled trial (RCT) was conducted at the Department of Gynaecology of the Karolinska Hospital in Stockholm, Sweden in 31 patients who had experienced dysmenorrhoea for more than 5 years, and were unable to use analgesics for a variety of reasons. ${ }^{14}$ Nineteen patients (mean age 30 years) received two treatments a few days before each of four consecutive menses, consisting of a different form of acupuncture stimulation for each cycle, in random order. Only five points were used, in the legs, abdomen and back. The different forms of stimulation were: manual (repeated rotation producing de qi), low frequency electrical, highfrequency electrical and periosteal, i.e. brief tapping of the periosteum with the needle tip. Before the fifth menstrual period, treatment was given according to patient preference. In another section of the study, 12 patients received a variety of forms of TENS, including 'placebo' TENS, in a routine similar to the acupuncture. In the acupuncture group there was significant improvement in pain, analgesic intake and subjective assessment. Direct statistical comparisons between the treatments were not made. There were similar improvements in the lowfrequency TENS group, but not the high-frequency or 


\begin{tabular}{|c|c|c|c|c|c|}
\hline & $\begin{array}{l}\text { Real } \\
\text { acupuncture }\end{array}$ & $\begin{array}{l}\text { Sham } \\
\text { acupuncture }\end{array}$ & $\begin{array}{l}\text { Standard } \\
\text { control }\end{array}$ & $\begin{array}{l}\text { Visitation } \\
\text { control }\end{array}$ & $\mathrm{p}$ \\
\hline Mean $( \pm$ SE) pretreatment pain score & $147 \pm 38$ & $155 \pm 41$ & $98 \pm 32$ & $118 \pm 26$ & $0.632^{\mathrm{a}}$ \\
\hline Mean $( \pm$ SE $)$ posttreatment pain score & $27 \pm 4.8$ & $92 \pm 28.8$ & $78 \pm 24$ & $117 \pm 26$ & $0.059 \mathrm{a}$ \\
\hline Number improved & $10 / 11$ & $4 / 11$ & $2 / 11$ & $1 / 10$ & $<0.05^{b}$ \\
\hline
\end{tabular}

aAnalysis of variance (ANOVA). bChi-squared test, real acupuncture versus all other groups. SE, standard error.

placebo TENS groups. Changes in the acupuncture and low-frequency TENS groups persisted for 3 months.

A Cochrane Review summarised these studies, saying they 'suggest benefit for this modality' but concluding that the evidence was insufficient. ${ }^{15}$ The same review included studies of TENS, and concluded that high-frequency TENS was effective for the treatment of dysmenorrhoea, though the number of trials was still small.

In one study of acupressure, 61 women were randomised to either a control group who had usual care, or an experimental group who wore a specially designed cotton Lycra panty brief ('Relief Brief') with 10 latex foam pads fixed over lower abdominal and lower back acupressure points that are used in treating dysmenorrhoea. ${ }^{16}$ The acupressure garment was worn on the first 3 days of menstruation, for two cycles, for as long as possible without discomfort. The mean duration worn over the 3 days was 29 hours, and four patients found the discomfort so great that they did not use it in the second cycle. Patients wearing the garment recorded highly significantly lower mean scores for 'worst' menstrual pain and for menstrual symptoms than the control group. More than two-thirds of the women wearing the garment reported at least $50 \%$ reduction in pain.

In a second acupressure study, 216 schoolgirls aged 14-18 years were either given ibuprofen regularly, or taught real or placebo (wrong points) acupressure, before each of three consecutive cycles. ${ }^{17}$ The severity of dysmenorrhoea was graded (on a four-point scale) at the end of therapy: $50 \%$ of the acupressure group reported zero grade, compared with $36 \%$ of the ibuprofen group and $18 \%$ of the sham acupressure group.

It is interesting to note that acupuncture was not shown to have any effect on menstrual blood flow in the one study ${ }^{14}$ in which it was estimated. There is no evidence from other published controlled trials that acupuncture has any effect on menorrhagia.

\section{Infertility}

Stener-Victorin compared electroacupuncture analgesia with standard alfentanil analgesia during oocyte aspiration. ${ }^{18}$ Although the effect on fertility was not the primary objective of the study, and so this finding must be viewed with caution, the electroacupuncture group were found to have a significantly higher chance of implantation and take-home baby rates (28/75 compared with $19 / 74$ in the control group).

Two gynaecologists in Germany frequently used ear acupuncture for treatment of infertility over 4 years. (The ear has been found to be useful site for giving acupuncture, which may be related to its vagal innervation.) The results of treatment for 45 infertile women were reviewed and compared with matched pairs who received standard hormonal therapy. ${ }^{19}$ The overall pregnancy rate was about $50 \%$, with no difference between the groups.

In a recent study involving 160 women undergoing in vitro fertilisation, 20 two sessions of acupuncture immediately before and after embryo transfer resulted in a significantly higher pregnancy rate $(42.5 \%)$ than in the control group who had no acupuncture $(26.3 \%)$. The effect on pregnancy rate could have been psychologically mediated since no placebo acupuncture was used in the controls.

\section{Menopausal symptoms}

Twenty-four menopausal women received either genuine electroacupuncture or superficial needling at incorrect points, and were followed up for 5 months. Scores for flushes by daily diary improved by $50 \%$ in both groups during the 12 weeks' treatment, but remained improved only in the acupuncture group, being better than the controls during this time though not significantly. The Kupperman index also improved, but there was no measurable effect on sleep dysfunction. Urinary secretion of calcitonin gene-related peptide, a potent vasodilator, increased in both groups during treatment but tended to return to normal afterwards.

The same research group ${ }^{21}$ repeated the study in 30 women with vasomotor symptoms. This time the acupuncture group showed no greater improvement than the controls for menopausal symptom scores or psychological well-being throughout the 6-month study. There was a significant superiority in mood scale scores during the first 12 weeks only.

Ten menopausal women with mild hypertension were included in a placebo-controlled, crossover study. ${ }^{22}$ Menopausal complaints and well-being significantly improved during treatment but this effect did not last for more than 2 months. No effect was seen on hypertension or on serum lipids, though there was a reduction in the secretion of noradrenaline in the acupuncture group.

\section{Discussion}

The number of controlled studies of acupuncture in gynaecological disorders is small, and their quality is limited. Particular weaknesses are small sample sizes (particularly for studies in the menopause) and lack of observer blinding. Patient blinding was designed into some trials though it was not verified. Practitioner blinding is difficult, though not impossible, in acupuncture studies. In contrast, some of these studies show interesting features: Helms ${ }^{13}$ included a visitation control group in an attempt to control for the attention of the practitioner, Pouresmail and Ibrahimzadeh $^{17}$ recruited a large number of schoolgirls from several schools of different socio-economic status, and Taylor et al. ${ }^{16}$ tested a novel garment designed to offer sustained pressure on the relevant acupuncture points.

In the absence of conclusive evidence for or against effectiveness for any of these conditions, it is worth considering possible mechanisms of action of acupuncture. The potential mechanisms of acupuncture for treatment of dysmenorrhoea are its central analgesic effect 6 and its reflex effects on the tissues, such as changes in blood flow. ${ }^{23}$ For hormonal problems, laboratory studies have shown that acupuncture stimulates the release of opioid peptides (such as beta-endorphin) in the arcuate nucleus of the hypothalamus. ${ }^{24}$ Since this is also the site for the gonadotrophin pulse generator, ${ }^{25}$ it is not unreasonable to explore whether acupuncture may have some effect on gonadotrophin-releasing hormone release and therefore 
may modify polycystic ovarian syndrome (PCOS). This possibility has received some support from laboratory experiments: EA stimulation prevented the expected rise in corticotrophin-releasing factor ${ }^{26}$ and nerve growth factor 27 concentrations in the ovaries of a rat PCOS model produced by oestradiol injection. Chen reported that $6 / 13$ anovulatory cycles in women responded to acupuncture, and were accompanied by autonomic effects as measured by skin temperature changes. ${ }^{28}$ By a similar mechanism one might expect a response in menopausal symptoms. ${ }^{29}$ Pointing to another possible mechanism of action, electroacupuncture was shown to be associated with a reduction of blood flow impedance (measured by pulsatility index) in the uterine arteries which may improve endometrial receptivity in preparation for embryo transfer. ${ }^{30}$

It is concluded that, within the stated limitations, the evidence suggests that acupressure has a specific effect in dysmenorrhoea but acupuncture is equivocal; that acupuncture is promising for infertility and was not shown to be inferior to standard hormonal therapy; and that acupuncture has not been shown to be effective for dysmenorrhoea but the trials are very small. In view of the theoretical basis of possible mechanisms, further research is justified in all these areas.

Statements on funding and competing interests

Funding. This project was partially funded by a Health Action Zone (HAZ) fellowship.

Competing interests. None identified.

References

1 Thomas KJ, Nicholl JP, Coleman P. Use and expenditure on complementary medicine in England: a population based survey. Complement Ther Med 2001; 9: 2-11.

2 Thomas K, Fall M, Parry G, et al. National survey of access to complementary health care via general practice. Sheffield: MCRU, 1995. Copies available from Medical Care Research Unit, Regent Court, 30 Regent Street, Sheffield S1 4DA, UK.

3 Ezzo J, Berman B, Hadhazy V, et al. Is acupuncture effective for the treatment of chronic pain? A systematic review. Pain 2000; 86: $217-225$.

4 Lee A, Done ML. The use of nonpharmacologic techniques to prevent postoperative nausea and vomiting: a meta-analysis. Anesth Analg 1999; 88: 1362-1369.

5 White A, Hayhoe S, Hart A, et al. Adverse events following acupuncture: prospective survey of 32000 consultations with doctors and physiotherapists. BMJ 2001; 323: 485-486.

6 Han J, Terenius L. Neurochemical basis of acupuncture analgesia. Annu Rev Pharmacol Toxicol 1982; 22: 193-220.

7 Cummings TM, White AR. Needling therapies in the management of myofascial trigger point pain: a systematic review. Arch Phys Med Rehabil 2001; 82: 986-992.

8 White A, Park J. Protocols for clinical trials of acupuncture. Acupunct Med 1999; 17: 54-58.

9 Le Bars D, Dickenson AH, Besson JM. Diffuse noxious inhibitory controls (DNIC). 1. Effects on dorsal horn convergent neurones in the rat. Pain 1979; 6: 283-304.

10 Streitberger K, Kleinhenz J. Introducing a placebo needle into acupuncture research. Lancet 1998; 352: 364-365.

11 Park J, White A, Stevinson C, et al. Validating a new non-penetrating sham acupuncture device: two randomised controlled trials. Acupunct Med 2002; 20: 168-174.

12 Hayhoe S, Box H. A questionnaire on medical acupuncture practice. Acupunct Med 1997; 15: 96-99.

13 Helms JM. Acupuncture for the management of primary dysmenorrhea. Obstet Gynecol 1987; 69: 51-56.

14 Thomas M, Lundeberg T, Björk G, et al. Pain and discomfort in primary dysmenorrhoea is reduced by preemptive acupuncture or low frequency TENS. Eur J Phys Med Rehabil 1995; 4: 71-76.

15 Proctor ML, Smith CA, Farquhar CM, et al. Transcutaneous electrical nerve stimulation and acupuncture for primary dysmenorrhoea (Cochrane Review). Cochrane Database Syst Rev 2002; CD002123.

16 Taylor D, Miaskowski C, Kohn J. A randomized clinical trial of the effectiveness of an acupressure device (relief brief) for managing symptoms of dysmenorrhea. J Altern Complement Med 2002; 8: 357-370.

17 Pouresmail Z, Ibrahimzadeh R. Effects of acupressure and ibuprofen on the severity of primary dysmenorrhea. J Tradit Chin Med 2002; 22: 205-210.
18 Stener-Victorin E, Waldenstrom U, Nilsson L, et al. A prospective randomized study of electro-acupuncture versus alfentanil as anaesthesia during oocyte aspiration in in-vitro fertilization. Hum Reprod 1999; 14: 2480-2484.

19 Gerhard I, Postneek F. Auricular acupuncture in the treatment of female infertility. Gynecol Endocrinol 1992; 6: 171-181.

20 Paulus WE, Zhang M, Strehler E, et al. Influence of acupuncture on the pregnancy rate in patients who undergo assisted reproduction therapy. Fertil Steril 2002; 77: 721-724.

21 Sandberg M, Wijma K, Wyon Y, et al. Effects of electro-acupuncture on psychological distress in postmenopausal women. Complement Ther Med 2002; 10: 161-169.

22 Kraft K, Coulon S, Wong AMK, et al. Der Einfluss einer standardisierten Akupunkturbehandlung auf Beschwerden, Blutdruck und Serumlipide hypertensiver, postmenopausaler Frauen. Forsch Komplementarmed 1999; 6: 74-79.

23 Jansen G, Lundeberg T, Kjartansson J, et al. Acupuncture and sensory neuropeptides increase cutaneous blood flow in rats. Neurosci Lett 1989; 97: 305-309.

24 Takeshige C, Oka K, Mizuno T, et al. The acupuncture point and its connecting central pathway for producing acupuncture analgesia. Brain Res Bull 1993; 30: 53-67.

25 Chang R, Chung PH, Rosenwaks Z. Role of acupuncture in the treatment of female infertility. Fertil Steril 2002; 78: 1149-1153.

26 Stener-Victorin E, Lundeberg T, Waldenstrom U, et al. Effects of electro-acupuncture on corticotropin-releasing factor in rats with experimentally-induced polycystic ovaries. Neuropeptides $2001 ; \mathbf{3 5}$ : 227-231.

27 Stener-Victorin E, Lundeberg T, Waldenstrom U, et al. Effects of electro-acupuncture on nerve growth factor and ovarian morphology in rats with experimentally induced polycystic ovaries. Biol Reprod 2000; 63: 1497-1503.

28 Chen BY, Yu J. Relationship between blood radioimmunoreactive beta-endorphin and hand skin temperature during the electroacupuncture induction of ovulation. Acupunct Electrother Res 1991; 16: $1-5$.

29 Wyon Y, Lindgren R, Lundeberg T, et al. Effects of acupuncture on climacteric vasomotor symptoms, quality of life, and urinary excretion of neuropeptides among postmenopausal women. Menopause 1995; 2: 3-12.

30 Stener-Victorin E, Waldenstrom U, Andersson SA, et al. Reduction of blood flow impedance in the uterine arteries of infertile women with electro-acupuncture. Hum Reprod 1996; 11: 1314-1317.

\section{herpes simplex can be more than a physical problem ...}

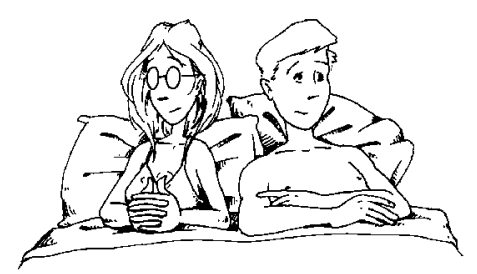

The Herpes Viruses Association helpline supplies information to patients and medical practitioners. Helpline volunteers who have the virus, including 'pregnancy helpliners' who have given birth, are trained to counsel and advise.

* "Patients with genital herpes suffer considerable psychological morbidity and the fact that they are able to receive very sophisticated and experienced counselling... has been extremely useful in helping them deal with their condition. The HVA has fulfilled this role admirably over the years . Prof. M W Adler MD FRCP FFPHM, UCL Medical School, London

* "Nobody does what they do, filling an important niche."

Dr Paul Simmons MB FRCP, St Bartholomew's Hospital, London

\section{helpline 02076099061}

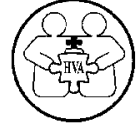

For leaflets, patient information cards or posters, write or send e-mail to:

HVA, 41 North Road, London N7 9DP marian@ herpes.org.uk

We often hear this comment "I wish l'd been told about you years ago" 